\title{
Clinical trials for carotid stenosis revascularization and relation to methods of stenosis quantification
}

\author{
Allan J Fox ${ }^{1,2^{*}}$ and Navneet Singh
}

\begin{abstract}
Severe carotid stenosis patients in the North American Symptomatic Carotid Endarterectomy Trial (NASCET) were shown to have a high risk of stroke and significant benefit from carotid endarterectomy. More than 20 years after the 1991 NASCET results for severe stenosis, there is a common claim to use the NASCET method to determine \% carotid stenosis, but without following the details necessary to properly identify the group most benefitting from carotid endarterectomy. NASCET interpreted for loss of diameter of the cervical ICA, near occlusion, and didn't calculate \% stenosis if present as it is fallacious. NASCET measured the distal ICA for well beyond the tapering ICA bulb where the ICA walls are parallel.

The pitfalls of stenosis quantification and differences between methods are problems of the ratio's denominator, and may potentially be resolved by the use of absolute measurements for stenosis on CTA or MRA. Furthermore, trials evaluating vessel wall components including intraplaque hemorrhage such as CAIN may add to or replace degree of stenosis for the prediction of cerebrovascular outcomes.
\end{abstract}

\section{Summary of NASCET's design, early stop, and surprisingly strong results}

The North American Symptomatic Carotid Endarterectomy Trial (NASCET) was designed to verify the superiority of carotid surgical revascularization to prevent stroke or death compared to best available medical management [1]. The severe stenosis arm of NASCET was stopped early by the National Institutes of Health (NIH) in February 1991, well ahead of the planned time [2]. This happened from documentation of stroke risk much worse than known before, in addition to surgical efficacy yielding significant surgical benefit for stroke prevention. NASCET's method of quantification (Figure 1) of carotid stenosis [2-4] was credited with defining the group of very high-risk cases in the medical group that had not previously been identified. The stenosis categorization method was also considered as a main factor for the trial's early success to find surgical benefit for the defined severe stenosis group. Yet perhaps NASCET's "severe stenosis" could have been called "very severe", since many operators have trouble reconciling the fact that

\footnotetext{
*Correspondence: ajfox@uwo.ca

'Department of Medical Imaging, Faculty of Medicine, University of Toronto, Toronto, Canada

${ }^{2}$ Neuroradiology Division, Department of Medical Imaging, Sunnybrook

Health Sciences Centre, 2075 Bayview Avenue, Toronto M4N 3M5, Canada
}

calculation of $70 \%$ or more stenosis appears worse than what many would call severe from a mere glance.

\section{Different Methods of Stenosis Measurement and Reconciliation of Stenosis with ECST}

NASCET paralleled the European Carotid Surgery Trial (ECST), also stopped for its severe group outcomes, although with notably less strength of outcome data than NASCET's [5]. Both studies identified the severe group as $70 \%$ stenosis or more, yet it was realized that their methods of quantifying \% stenosis differed, making the studied groups quite different from each other as well as the strength of the surgical results. NASCET isolated a more severe stenotic group with greater stroke risk and greater surgical benefit. For example, the $70 \%$ stenosis cut-off for ECST corresponded to about $40 \%$ stenosis for NASCET, while NASCET's 70\% stenosis was about $85 \%$ ECST [6]. Given that the NASCET moderate stenosis group, measured as 50-69\% stenosis, hardly had slight benefit of surgery [7], it is easy to understand why ECST's severe group showed a muted benefit of surgery compared to NASCET, since it contained both NASCET's severe and moderate groups [3,7].

There had always been different ways to assign \% carotid stenosis [1,3]. The blatant differences between NASCET and ECST methods and results were striking 


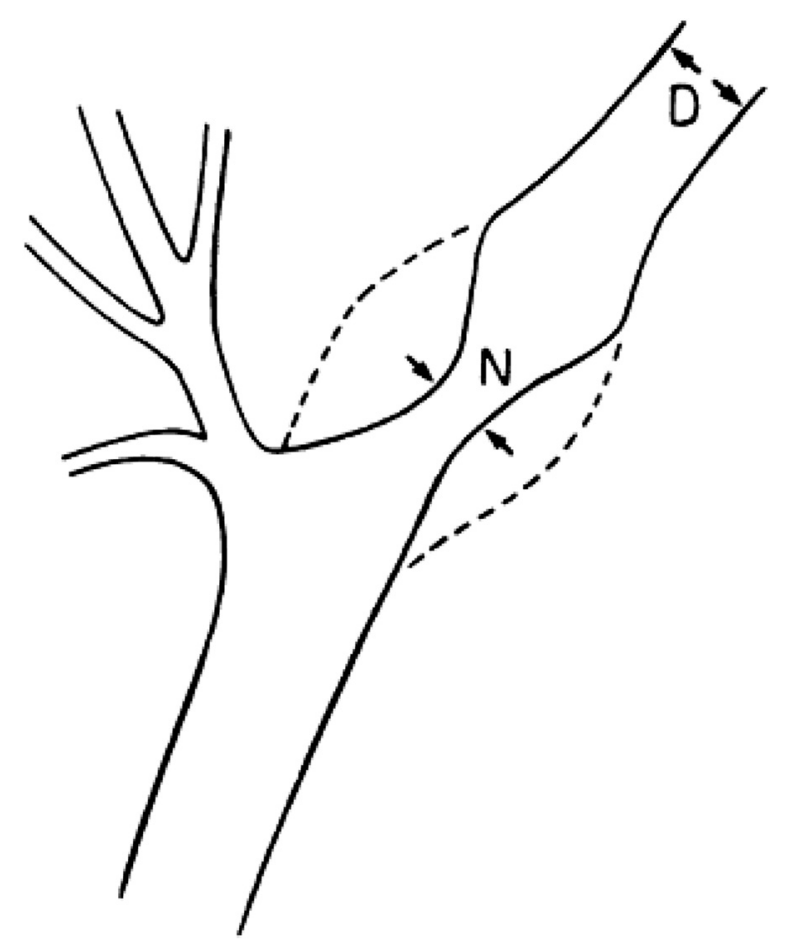

Figure 1 Shows a conceptualized drawing of the calculation of $\%$ stenosis $=(1-N / D) 100$, with $N$ as the narrowest observed diameter and $\mathrm{D}$ as the diameter of the "normal" internal carotid diameter well beyond the bulb where the walls are parallel. Reproduced with permission from Radiology [3].

[1-7]. A problem is that the multiple ways of calculating \% each has its own logic $[3,7,8]$. NASCET chose a method that effectively quantifies stenosis based on the luminal reduction compared to the internal carotid artery (ICA) distal outflow (Figure 1). ECST's method measures from luminal reduction of the stenosis and compares it to the unseen ICA bulb width on standard angiography (the stenotic atheroma covers it). This ECST \% is derived from a denominator of up to twice the diameter of the distal ICA, with ICA bulb being the largest part of the artery.

NASCET's method is most commonly used today as it relates to the higher stroke risk group and stronger surgical benefit found in NASCET. In a sense, all methods are arbitrary and anyone can use what they prefer, however, the outcome results of both NASCET and ECST are very specific to the respective methods used. It seems incorrect to use NASCET's clinical results unless used with NASCET's stenosis method. Indeed, analysing the results together from both NASCET and ECST [8] for combined analysis, NASCET's method was used for all cases.

In effect, NASCET defined its severe group in a way not previously highlighted, and it could be said that NASCET's "severe" group is really "very severe", while its moderate group could give the impression of very prominent stenosis if identified just by the eye, without adhering to measurements and calculation of $\%$ stenosis $[3,4]$.

\section{Role of stenosis measurement in NASCET's success}

The early NASCET stop by NIH for severe stenosis in 1991 was based on NASCET's stenosis degree for 70\% or more with the 2-year stroke risk being over $20 \%$ of cases for $70-79 \%$ stenosis, $30 \%$ for cases for $80-89 \%$ stenosis, and $40 \%$ of cases for $90-99 \%$ of cases [2,3]. The surgical group showed 2-year stroke risk in the 10\% range for all severe stenosis degrees, including peri-operative risks, yielding a two-year stroke prevention benefit of $14 \%, 18 \%$, and $26 \%$ of cases for each of the three deciles of stenosis degree [2].

While the NASCET group with 50-69\% stenosis showed an overall modest benefit to prevent stroke [7], this was negative for some studied clinical groups, while there was little latitude for surgical complications that could easily erase the muted benefit for all cases in this study group. The $70 \%$ stenosis threshold remained a strong criterion for surgery.

Both the incidences of stroke risk and surgical success to prevent stroke were substantially greater than had been predicted in the planning stages for the trial. In effect, NASCET through its \% stenosis method (Figure 1) was original to study this group of very severe stenosis that greatly benefited from surgical endarterectomy.

\section{Pitfalls of NASCET measurement}

1) Lack of compliance with NASCET's stenosis Methods:

Perhaps the biggest pitfall of using the NASCET method for \% stenosis is lack of compliance [4] to the specific details of how NASCET used its method. A stenosis of NASCET moderate degree could naively be called "severe" to the eye if not measured. Indeed, the observations of NASCET's chief neuroradiological investigator (AJF) is that to satisfy the diameter ratio criteria of NASCET, the residual stenosed lumen needs to be reduced to little more than a thread; if the reduced lumen has substance that is clearly seen, it is unlikely to fulfil measurement criteria for $70 \%$ or more.

\section{2) Lack of Assessment for Near Occlusion:}

The nearly complete collapse of ICA lumen beyond a very severe stenosis is (Figure 2) known by with a variety of names, called near occlusion in NASCET [1,3,9-12]. Less well identified is a lesser physiological loss of diameter of ICA beyond severe stenosis (Figures 3,4) that can be considered "normal-looking" but otherwise shows partial collapse $[11,12]$. Both categories are called near occlusion in NASCET [1,3,9-12], representing complete 


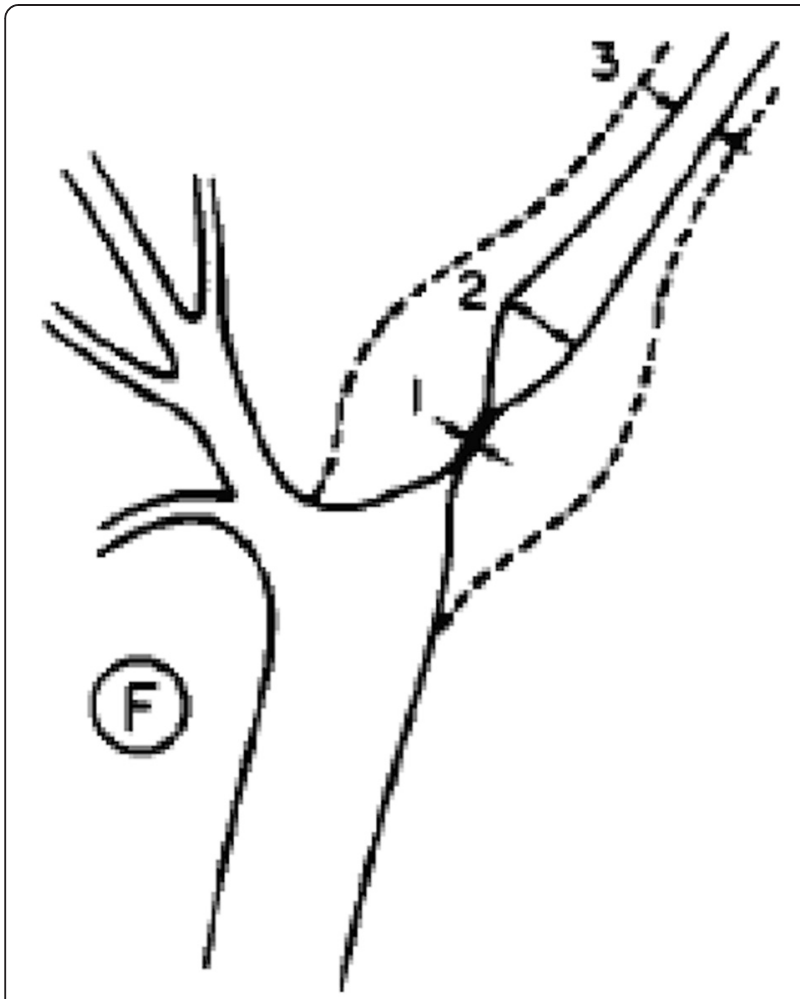

Figure 2 Shows a conceptualized drawing of "near occlusion" as a collapsed lumen beyond very severe stenosis with flow reduction associated with presumed physiological loss of diameter of the distal ICA. NASCET recognized that any \% stenosis calculation from such a reduced distal ICA lumen was flawed.

Figure 2 is a reproduced part of a figure in Stroke (1). "Promotional and commercial use of the material in print, digital or mobile device format is prohibited without the permission from the publisher

Lippincott Williams \& Wilkins. Please contact

journalpermissions@lww.com for further information".

and partial collapse. They can't be correctly measured and calculated for \% stenosis because the distal ICA diameter is too small and not truly normal. NASCET understood that no measurements could be correctly taken for near occlusion [1,3,9-12] because to do so would be fallacious. Yet many still do not recognize partial collapse as near occlusion and go ahead to fallaciously calculate \% stenosis. As such the yielded \% can be substantially less than severe stenosis [4]. To avert this lack of compliance, NASCET suggested that before any stenosis be measured it should be first interpreted for presence or not of the subtle near occlusion $[1,3,4]$.

By ignoring these subtler near occlusion cases and blindly applying measurements, the partly collapsed denominator for \% calculation will artificially reduce the \% stenosis $[3,4]$, with some cases of severe stenosis fallaciously calculated as $60 \%$ or even less. There are even published reports suggesting that NASCET's method can underestimate stenosis degree; these, however, are really reports by operators and authors who did not pay

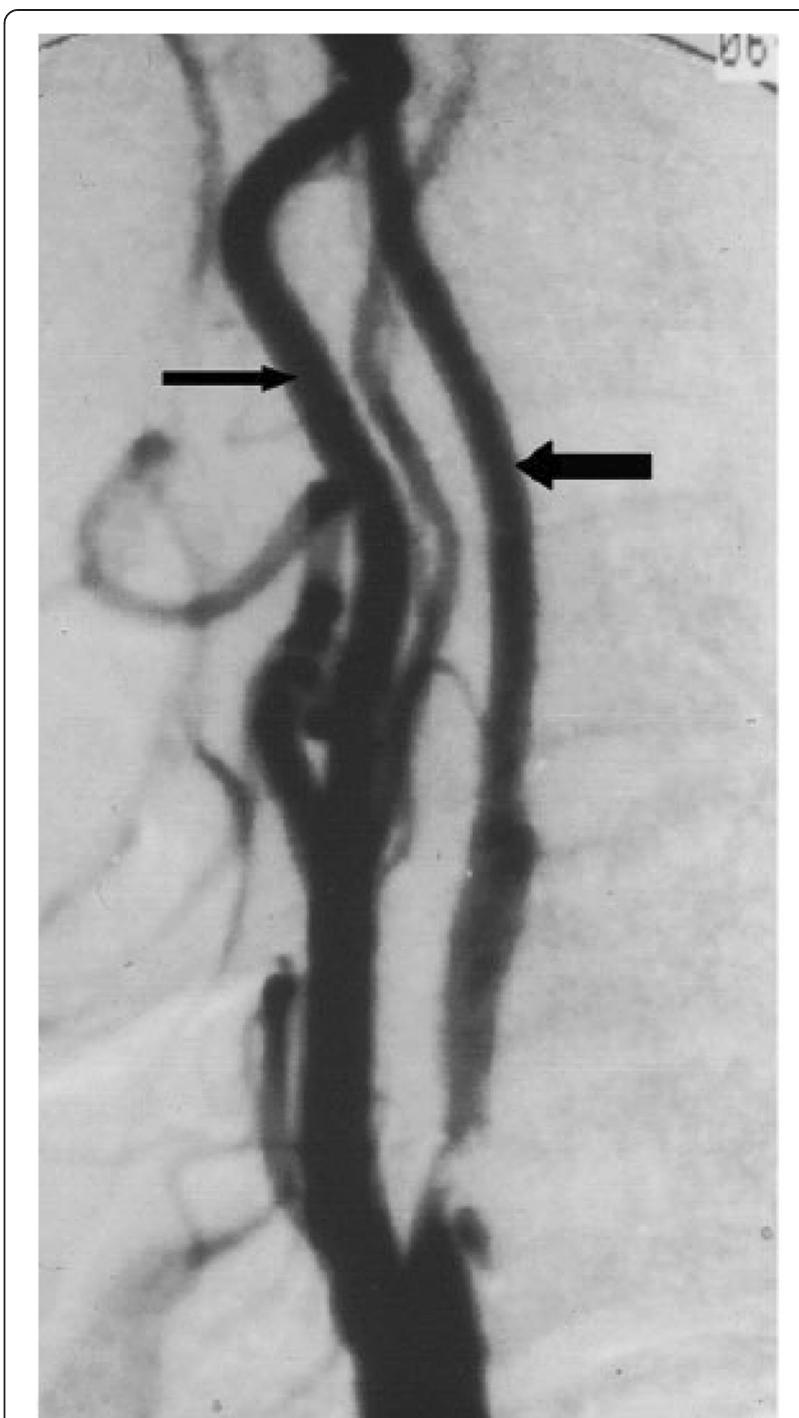

Figure 3 Shows less profound near occlusion with an angiogram of the "normal-appearing" internal carotid well beyond a prominent ICA bulb stenosis, with its diameter (large arrow) narrower that the external carotid diameter nearby, implying partial collapse of the distal ICA. The ICA diameter should be substantially larger than ECA diameter. Picture reproduced with permission from AJNR [11].

attention to or comply with NASCET's instructions to interpret for near occlusion before applying any measurements. This is needed to avoid false measurements $[1,3,4,11]$. Claiming to use NASCET's approach but failing to identify near occlusions could result in management decisions that differ from NASCET clinical outcome categories.

3) Denominator Measurement for \% Stenosis:

NASCET chose a denominator to calculate \% stenosis using the distal ICA diameter well beyond the bulb 


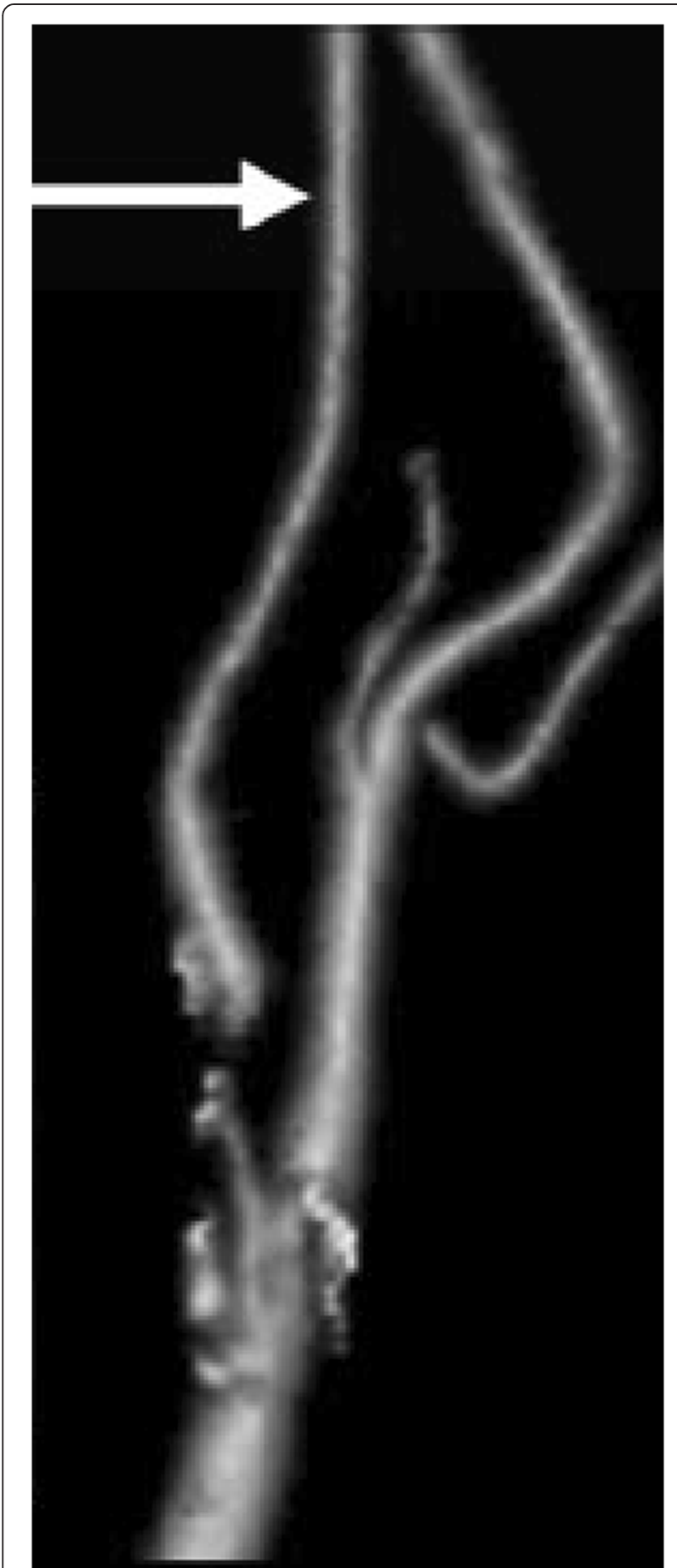

Figure 4 Shows a reformatted image from a CTA "normalappearing" internal carotid well beyond a prominent ICA bulb stenosis, with its diameter (large arrow) narrower that the external carotid diameter nearby, implying partial collapse of the distal ICA. ICA diameter should be substantially larger than ECA diameter. Picture reproduced with permission from AJNR [12]. where the walls are parallel $[1,3,4]$. ICA bulb is an anatomical aberration $[1,3]$ where the artery becomes much larger than its inflow parent CCA, and becomes much smaller than its outflow ICA. The transition from wide bulb to narrower outflow ICA is a gradual tapering vessel. To choose a changing diameter structure for $\% \mathrm{cal}-$ culation purposes seems both illogical and incorrect [4] when one can choose a parallel part of the artery, where the walls are parallel. Measuring ICA where it is larger than the distal ICA where walls are parallel falsely increases the calculated \% stenosis [4]. Claiming to use NASCET's approach but failing to measure the distal normal well beyond the bulb where the walls are parallel could result in management decisions that differ from NASCET clinical outcome categories.

\section{Other Methods and New Imaging Methods with Capability for Measurement}

\section{1) Millimetre (mm) Diameter Measurements:}

NASCET outcome results [2,7] are considered a "bible" of stroke prevention management for symptomatic patients with carotid stenosis. Misuse of NASCET \% stenosis calculations [4] exists. There is reluctance by many to abandon NASCET \% stenosis because NASCET outcomes derived from \% stenosis. In the days of standard angiography, \% calculation made sense: old film angiography had uncertainty of magnification factors for real measurements, while digital subtraction angiography (DSA) was basically expressed in pixels and not real $\mathrm{mm}$. The pitfalls of NASCET \% stenosis arise mainly from the denominator; yet the numerator essentially expresses the lumen [3]. Now in an era when real mm are part of CTA (Figure 5) and MRA, it seems appropriate and logical to eliminate the problem denominator and consider the quantification of stenosis based on $\mathrm{mm}$ diameter of the residual lumen. That has been done in a series of experiments using a CTA stenosis database [12-16] and comparing $\mathrm{mm}$ stenosis with other derived stenosis methods. The CTA method shown in Figure 5 [13] uses measurements from thin axial source images which have highest spatial resolution, guided by reformats in other directions. Today we get accurate $\mathrm{mm}$ diameters; why persist with a \% method that was useful when DSA did could not give accurate $\mathrm{mm}$ when now CTA gives $\mathrm{mm}$, especially since problems with compliance with the NASCET approach are due to variable and inconsistent ways to determine the denominator for \% ratio?

The CTA approach also includes improvements to view a stenosis compared to angiography as was used in NASCET. NASCET used the narrowest diameter from available angiographic views, which were often quite limited, while CTA now allows a full cross-sectional look 


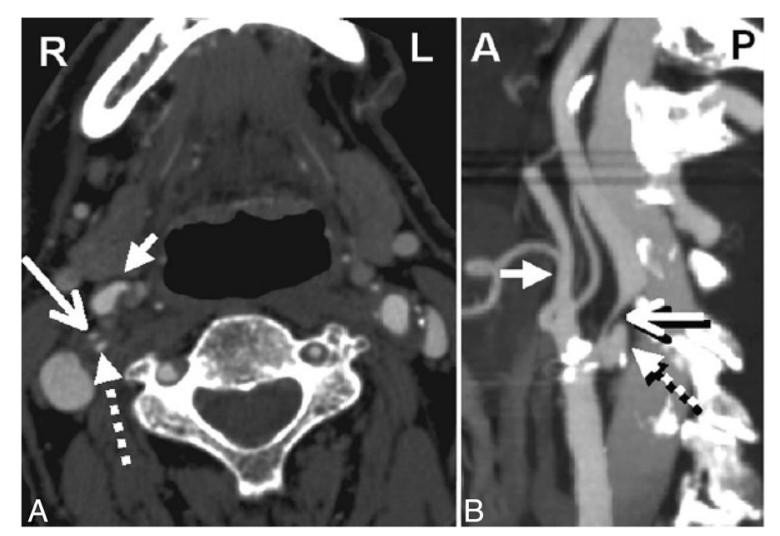

Figure 5 shows axial (A) and sagittal (B) reformatting of a right ICA bulb stenosis with large plaque ulcer/uplifted plaque. The larger solid arrow shows the reduced ICA lumen at the stenosis, readily measured by $\mathrm{CT}$ caliper tool, more accurate from the axial source image. The dashed arrow indicates the ulcerated plaque and small arrow the ECA. Picture reproduced with permission from AJNR [13]. The thin axial source images are used for measurement as they have the highest spatial resolution. to choose the narrowest diameter from unlimited angles [13]. CTA shows soft tissue in addition to lumen, so that outside artery walls can be seen [15], not visible with standard or subtraction angiography. Plaque ulceration can potentially be seen more often than just by chance getting the right angle to show it. Yet despite these advances and logical explanations and despite the publication of the Bartlett work on CTA mm stenosis [13-16] there is continued reluctance to abandon \% stenosis.

2) Other Methods for \% Stenosis Calculations:

There remain multiple other ways to express \% stenosis, using ratios of carotid artery and different basic measurements $[3,5,6]$. They remain alternatives, each with their own logic of approach, their own following, and all produce \% stenosis numbers different from NASCET for the same stenosis [3,6]. All methods are arbitrary, including NASCET's method. The justification to use NASCET's method comes from the NASCET outcome results and their statistical strength. Indeed, while ECST initially used a different method, for meta-analysis it converted to NASCET's approach $[6,8]$ recognizing that NASCET outcome results of stroke risk and surgical benefit was substantially stronger identifying cases with the NASCET method [2] than results with ECST [5].

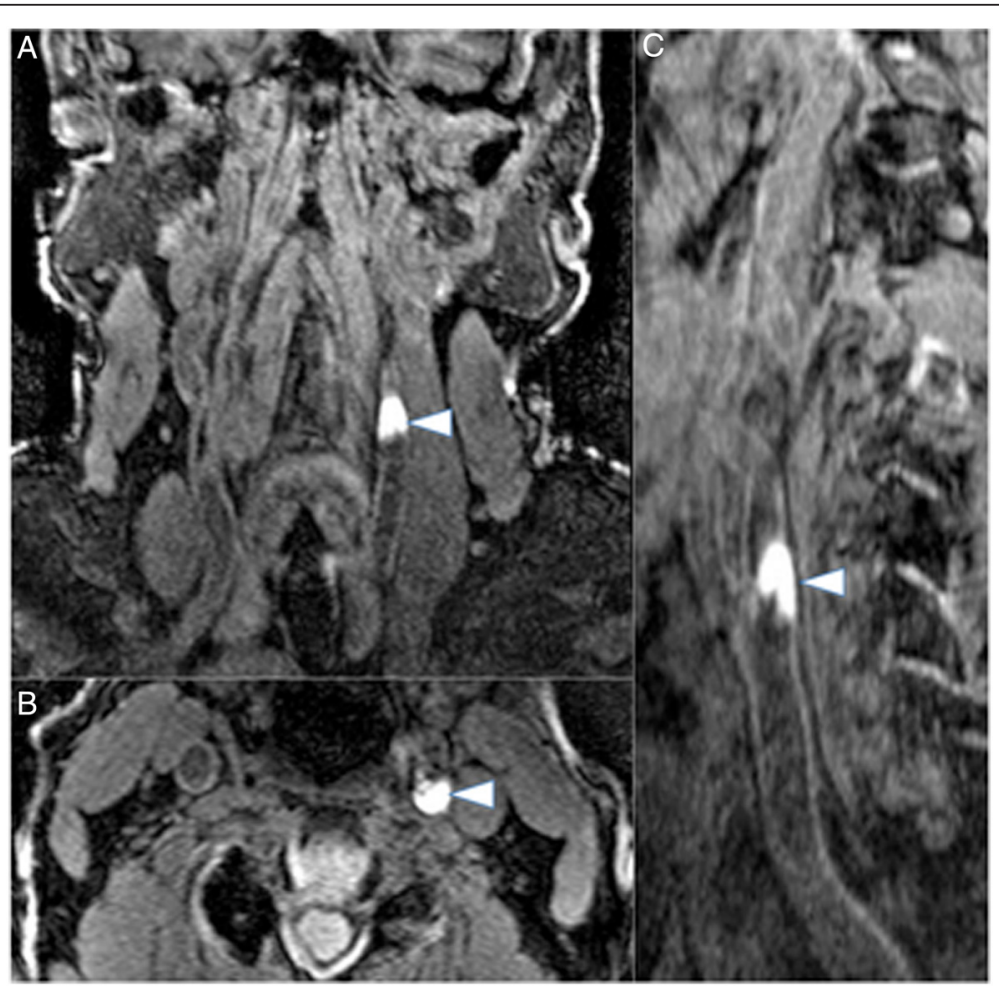

Figure 6 shows multiplanar images (coronal (A), axial (B) and sagittal (C) demonstrating MR-depicted intraplaque hemorrhage (IPH) (arrowheads). IPH is indicated by the high signal intensity of methemoglobin on this T1-weighted gradient echo MRI technique. Figure reproduced with permission from the International Journal of Cardiovascular Imaging [26]. 
In effect, anyone can define an alternate method to express \% stenosis, derive different numbers from NASCET for stenosis degree, and use them as long as they do not use their \% stenosis matched with NASCET outcome results, not scientifically or clinically correct $[3,4]$. Yet all \% stenosis methods utilize the narrowest measured diameter of ICA bulb stenosis. There would be no remaining dispute of which denominator to use for calculation if all would concentrate on the $\mathrm{mm}$ stenosis and not choose a denominator [13-16].

\section{3) Potential Acceptance of mm Stenosis:}

It seems that NASCET's excellent outcome results command greater popular credibility than the logical and anatomical reasons for switching to $\mathrm{mm}$ stenosis. That suggests that a similarly credible result of a new randomized trial for carotid stenosis management may be the only way to establish mm stenosis as a new standard, as long as the new trial includes CTA (or MRA although the measurement resolution of CTA is higher than commonly used MRA), will derive both $\mathrm{mm}$ and NASCET \% stenosis, and will relate stenosis to outcomes. It is not expected that NASCET will be redone. A related study is the new CREST, which will include CTA for many of its cases. The CREST trialists will have an opportunity to show outcomes along with secondary analyses between \% stenosis, mm stenosis, and Doppler velocities.

\section{4) Ultrasound Depiction of \% Stenosis:}

Doppler/duplex ultrasound measures velocity to determine stenosis, not anatomical mm measurements. There is technical variability of technologist ability to find a maximal velocity. Doppler measures velocity, not anatomical diameter. Yet, the clinical trials that determined management for carotid stenosis are studied as \% stenosis, so there are common attempts to express ultrasound results as \% stenosis, even though there is no linear conversion. Modern ultrasound machines include software tables to convert velocity to \% stenosis, with the derivation of the original tables hard to verify. The real measurements of Doppler are velocities. Yet Dopplers are often reported as \% stenosis very distant from original angiographic comparisons for those tables, and with uncertainty of the relationship to the NASCET method [17].

\section{5) Vessel Wall Content-“Unstable Plaque":}

The concept of the instability of plaque content as being an important risk factor for carotid stenosis is undergoing study. Intra-plaque haemorrhage (IPH) has long been presumed as such a risk factor, though to identify it was previously difficult. IPH seems to be more prevalent in higher grades of carotid stenosis. However, groups studying IPH appear to focus more on demonstrating that IPH is a risk factor for plaque progression defined by vessel wall or plaque volumes $[18,19]$.

Now the ability to image plaque hematoma in the methemoglobin phase [20] has brought in a new era (Figure 6) [21]. IPH may further risk stratify within stenosis degree groups. IPH has been shown to predict cerebrovascular outcomes within various specific stenosis groups [22-25]. IPH, in conjunction with stenosis, may provide precise cerebrovascular risk stratification. Larger and/or more systematic trials are now underway that should be able to shed light including CAIN [26]. CAIN is a multi-centre, pan-national serial imaging trial of the carotids and brain that includes investigation of clinical and imaging cerebrovascular outcomes [26].

\section{Conclusions}

NASCET outcome results for symptomatic carotid stenosis are most accepted to determine surgical or interventional management, yet those results are tied to a particular "severe" way to determine \% stenosis degree $[2,7,8]$. The so-called NASCET approach to carotid stenosis quantification seems to have less than optimal compliance [4], and it is possible that many patients may be sent to surgical treatment based on NASCET results, yet for which they do not have the indications, because of lack of compliance of \% stenosis calculations [4]. Mm stenosis methods [13] have been suggested as replacements especially because they don't have the pitfalls of the denominator for ratio calculation. While this is logical and incorporates the $\mathrm{mm}$ calibrations inherent in cross-sectional imaging, it may need a new clinical outcome treatment study that uses $\mathrm{mm}$ stenosis in order to change user preference of $\mathrm{mm}$ over \% stenosis. New studies may also find that plaque imaging is an important predictor of stroke from carotid stenosis [18-26], perhaps even as or more important than stenosis degree.

\section{Competing interests}

Both authors declare that they have no competing interests.

\section{Authors' contributions}

Both authors contributed to the manuscript, read, and approved the final manuscript.

Received: 10 November 2014 Accepted: 7 January 2015 Published online: 21 October 2015

\footnotetext{
References

1. North American Symptomatic Carotid Endarterectomy Trial (NASCET) Steering Committee. North American symptomatic carotid endarterectomy trial: methods, patient characteristics, and progress. Stroke. 1991;22:711-20.

2. North American Symptomatic Carotid Endarterectomy Trial Collaborators. Beneficial effect of carotid endarterectomy in symptomatic patients with high grade carotid stenosis. N EnglJ Med. 1991;325:445-53.
} 
3. Fox AJ. How to measure carotid stenosis. Radiology. 1993;186:316-8.

4. Fox AJ, Symons SP, Aviv RI, Howard P, Yeung R, Bartlett ES. Falsely claiming use of NASCET percentage stenosis method. Radiology. 2009;253:574-5.

5. European Carotid Surgery Trialists' Collaborative Group. MRC European carotid surgery trial: interim results for symptomatic patients with severe (70-99\%) or with mild (0-29\%) carotid stenosis. Lancet. 1991;337:1235-43.

6. Rothwell PM, Gibson RJ, Slattery J, Warlow CP. Prognostic value and reproducibility of measurements of carotid stenosis. A comparison of three methods on 1001 angiograms. European Carotid Surgery Trialists' Collaborative Group. Stroke. 1994;25:2440-4.

7. Barnett HJM, Taylor DW, Eliasziw M, Fox AJ, et al. Benefit of carotid endarterectomy in patients with symptomatic moderate or severe stenosis. N Engl J Med. 1998;339:1415-25.

8. Rothwell PM, Eliasziw M, Gutnikov SA, Fox AJ, Taylor DW, Mayberg MR, et al. Analysis of pooled data from the randomised controlled trials of endarterectomy for symptomatic carotid stenosis. Lancet. 2003;361:107-16.

9. Morgenstern LB, Fox AJ, Sharpe B, Eliasziw M, Barnett HJM, Grotta JC. The risks and benefits of carotid endarterectomy in patients with near-occlusion of the carotid artery. Neurology. 1997:48:911-5.

10. Henderson RD, Eliasziw M, Fox AJ, Rothwell PM, Barnett HJM, for the NASCET group. Angiographically-Defined Collateral Circulation and the Risk of Stroke in Patients with Severe Carotid Artery Stenosis. Stroke. 2000;31:128-32.

11. Fox AJ, Eliasziw M, Rothwell PM, Schmidt MH, Warlow CP, Barnett HJM. Identification, Prognosis, and Management of Patients with Carotid Artery Near Occlusion. AJNR. 2005;26:2086-94.

12. Bartlett ES, Walters TD, Symons SP, Fox AJ. Diagnosing Carotid Stenosis Near-Occlusion by Using CT Angiography. AJNR. 2006;27:632-7.

13. Bartlett ES, Walters TD, Symons SP, Fox AJ. Quantification of Carotid Stenosis on CT Angiography. AJNR. 2006;27:13-9.

14. Bartlett ES, Symons SP, Fox AJ. Correlation of Carotid Stenosis and CrossSectional Areas with CT Angiography. AJNR. 2006;27:638-42.

15. Bartlett ES, Walters TD, Symons SP, Fox AJ. Carotid Stenosis Index Revisited With Direct CT Angiography Measurements of Carotid Arteries to Quantify Carotid Stenosis. Stroke. 2007;38:286-91.

16. Bartlett ES, Walters TD, Symons SP, Aviv AJ, Fox AJ. Classification of carotid stenosis by millimeter CT angiography measures: effects of prevalence and gender. AJNR. 2008;29:1677-83.

17. Dreisbach JN, Seibert CE, Smazal SF, et al. Duplex sonography in the evaluation of carotid artery disease. AJNR. 1983;4:678-80.

18. Takaya N, Yuan C, Chu B, Saam T, Polissar NL, Jarvik GP, et al. Presence of intraplaque hemorrhage stimulates progression of carotid atherosclerotic plaques: a high-resolution magnetic resonance imaging study. Circulation. 2005; 111:2768-75.

19. Boussel L, Arora S, Rapp J, Rutt B, Huston J, Parker D, et al. Atherosclerotic plaque progression in carotid arteries: monitoring with high-spatialresolution MR imaging-multicenter trial. Radiology. 2009;252:789-96.

20. Moody AR, Murphy RE, Morgan PS, Martel AL, Delay GS, Allder S, et al. Characterization of complicated carotid plaque with magnetic resonance direct thrombus imaging in patients with cerebral ischemia. Circulation. 2003; 107:3047-52.

21. Singh N, Moody AR, Rochon-Terry G, Kiss A, Zavodni A. Identifying a high risk cardiovascular phenotype by carotid MRI-depicted intraplaque hemorrhage. Int J Cardiovasc Imaging. 2013;29(7):1477-83.

22. Lindsay AC, Biasiolli L, Lee JM, Kylintireas I, Maclntosh BJ, Watt H, et al. Plaque features associated with increased cerebral infarction after minor stroke and TIA: a prospective, case-control, 3-T carotid artery MR imaging study. JACC Cardiovasc Imaging. 2012;5:388-96.

23. Gupta A, Baradaran H, Schweitzer AD, Kamel H, Pandya A, Delgado D, et al. Carotid plaque MRI and stroke risk: a systematic review and meta-analysis. Stroke. 2013:44:3071-7.

24. Singh N, Moody AR, Gladstone DJ, Leung G, Ravikumar R, Zhan J, et al Moderate carotid artery stenosis: MR imaging-depicted intraplaque hemorrhage predicts risk of cerebrovascular ischemic events in asymptomatic men. Radiology. 2009;252:502-8.

25. Singh N, Moody AR, Zavodni AE. Magnetic Resonance Imaging of Carotid Atherosclerosis and the Risk of Stroke. Current Cardiovascular Imaging Reports. 2012;6:25-33.

26. Tardif JC, Spence JD, Heinonen TM, Moody A, Pressacco J, Frayne R, et al. Atherosclerosis imaging and the Canadian Atherosclerosis Imaging Network. Can J Cardiol. 2013;29:297-303.

\section{Submit your next manuscript to BioMed Central and take full advantage of:}

- Convenient online submission

- Thorough peer review

- No space constraints or color figure charges

- Immediate publication on acceptance

- Inclusion in PubMed, CAS, Scopus and Google Scholar

- Research which is freely available for redistribution

Submit your manuscript at www.biomedcentral.com/submit 